\section{Simone Barratt}

is the managing director of

$e$-Dialog and a recognised

thought-leader in digital direct

marketing. Simone launched e-

Dialog in 2001, and from the lows

of the dot-com bust has grown

the UK business to be recognised

by industry analysts as the top-

performing Email Marketing

Services Provider. Simone

provides senior consultancy to

clients including British Airways, RBS, Boots and Reuters, and has

also expanded the company's

expertise into digital direct

marketing across Europe, the

Middle East and Africa - serving

clients such as Dell, Expedia, Nike and HP in some 22 countries.

Steve Davis

was named Executive Vice

President, International, for GSI

Commerce, and President for GSI

Commerce Europe in April 2007.

Earlier he served as Senior Vice

President, Partner Services, from

December 2004 to March 2007.

He also served as a consultant

from February 2004 to December

2004 and as Senior Vice President

of Marketing from January 2000

to February 2004. From June

1996 to January 2000, Mr Davis

held a number of management

positions at Just for Feet Inc., a

specialty sporting goods retailer

based in Birmingham, $A L$, where

he last served as Vice President of

Marketing.

Keywords: e-commerce,

e-communications,

Database marketing,

Retail Strategy, Digital, CRM

Simone Barratt

e-Dialog EMEA

247 Tottenham Court Road

London W1T 7AX, UK

Tel: +44 (0)203 2196222

E-mail: sbarratt@e-dialog.com

Web: www.e-Dialog.com

\section{Connected Commerce: The intersection of e-commerce and e-communication}

\author{
Simone Barratt and Steve Davis \\ Received: 21 October 2008
}

\begin{abstract}
Only a handful of brands are providing their customers with highly personalised digital experiences. From their website, to email and mobile messaging, they've put the customer's interests at the forefront of their digital strategy. They've changed the fundamentals of their digital communications with their customers by creating an environment of Connected Commerce. The results have been exceptional customer loyalty, sales growth and profits that outpace those of their peers. The vast majority of companies are, however, still playing catch-up. Many have 'customercentricity' somewhere in their vision statements, but they've not yet made the necessary commitments to bring customer relevance to the face of their digital brands. Their results reflect this in dwindling loyalty, sales and profits. The good news for these companies is that it's not too late to make the shift and push to the front of their industries. This paper explores what it takes to move from internally driven promotions to customer-centric interactions. This shift requires taking advantage of technology advancements and process improvements, but also a new mindset about one's marketing approach.

Journal of Direct, Data and Digital Marketing Practice (2009) 10, 249-261. doi:10.1057/dddmp.2008.42
\end{abstract}

\section{Marketing mindset: A narrow focus}

One of the reasons marketers fail to make progress towards a customercentric model is that they are trying to be attentive to their entire audience. They make efforts to customise their content, but given the scale of their databases are limited in their ability to deliver any meaningful level of personalisation. We refer to this as a 'broad and shallow' approach. Efforts to be all-inclusive result in everyone being disappointed with their experience, including your most important customers.

Typical e-mail subscriber behaviour serves as a good example of waning consumer interest due to irrelevance. As shown in Figure 1, subscribers who receive blanket messaging demonstrate a precipitous drop in response within 2-3 months of opting in. The marketer has 


\section{Many marketers believe blanket mailing their database is harmless, they are wrong}

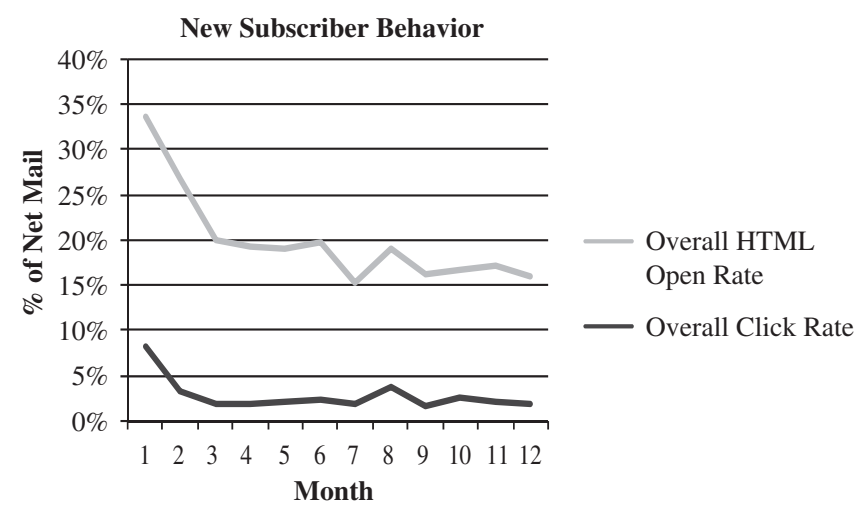

Figure 1: Typical new subscriber disengagement due to irrelevant marketing

trained them to disregard their messages, and the chance of recovering a subscriber's interest after this initial experience is slim.

So, while many e-mail marketers believe that blanket mailing their entire database is harmless, they are wrong. E-mail subscribers read only a finite number of brands' e-mails: those they find worthwhile. As such, poor messaging relevance is a sure-fire way to deplete the future value of your database. ${ }^{1}$

Instead, we suggest a 'narrow and deep' strategy. 'Narrow' means focusing on a select group. And 'deep' means creating a truly relevant experience. In short, identify your best opportunities and cater to them exclusively. This is the mindset of value-based segmentation. Although this principle is fundamental to traditional direct marketers, the approach seems to have lost its perceived necessity in the world of digital. This is a great tragedy, because digital marketing offers an entirely new dynamic to this approach, something traditional channels cannot. It offers real-time identification of your best opportunities and the ability to target them.

\section{Think like a shopkeeper}

This concept is not unlike the situation that a small shopkeeper faces everyday. The shopkeeper conducts direct marketing to generate awareness and drive traffic to his store. This is a broad targeting effort, based on store proximity and perhaps a couple of other variables. When someone walks into the store, however, that person instantly becomes his most valued customer. His focus shifts from getting people into the store to selling to that one customer.

The digital marketer's position is not so different. The people who are on your website right now are your most important customers. Some are more important than others, but collectively they require your attention. There are only a handful of outcomes from their site visit:

(1) They convert via e-commerce and perhaps opt into e-mail.

(2) They leave, but have some intention of buying from you through another channel. 
This practice of differentiation is likely the most profitable approach
(3) They leave to compare you to another merchant.

(4) They leave thinking that you don't have what they want.

(5) They opt into e-mail and leave, perhaps because they're interested in a variety of things from your brand, or perhaps they're considering a significant purchase that requires more research.

Just as for the shopkeeper, the outcome of this website visit is highly dependent on your ability to cater to the customer's needs. If you do a good job, your chances for conversion increase dramatically. If you leave them to browse and decide for themselves, your chances lessen.

But let's put the shopkeeper in the marketer's shoes. What happens when the shopkeeper is vastly outnumbered? He does not try to yell to the crowd about what's on sale that day. He probably addresses each customer based on when (s)he entered the store. The more discerning shopkeeper might, however, survey the store and pinpoint the people who are browsing the more profitable items. He might recognise a loyal customer who buys big-ticket items. Perhaps he even discriminates based on different shoppers' clothing and appearances. Whether appropriate or not, this practice of differentiation is likely the most profitable approach to his business, you can bet that if the shopkeeper somehow knew which of the customers in his store were most likely to purchase and which of the purchasers were buying the most profitable items, he would focus his efforts on those customers.

As a digital marketer, you have that discerning capability. You also have the ability to cater to the needs of many at the same time. Suppose for a moment that the shopkeeper identifies a customer who is interested in a set of expensive golf clubs. He describes the benefits of the various clubs to the shopper, helping him or her make a decision. Great work! The sale is made. Now suppose the next day another shopper comes in and is looking at golf clubs, but this time the shopkeeper is tied up talking to someone else about low-end hiking boots. Clearly, the shopkeeper cannot abandon his hiking customer because a more profitable opportunity has come along. Imagine, though, if the shopkeeper could clone himself so that the clone could repeat the exact benefits of the golf clubs as he had done the day before.

\section{The customer-centric approach}

$\mathrm{OK}$, this isn't the X-Files. But in effect, the digital marketer can clone an online shopping experience. Here's how with today's technology:

(1) Your website should identify a returning visitor (most of the time).

(2) Your website should infer from previous visits what this visitor might be interested in. This might be a specific product, a product category, a colour or a price range.

(3) Your website should also use any self-declared information from the visitor to draw these conclusions. 


\section{We recommend that a percentage of your efforts migrate to focus on 'in-consideration' opportunities}

(4) Finally, even if your shopper is not identified as a repeat visitor, your website should use the behaviours of others who have similar characteristics to this shopper to present appropriate products and offers.

This concept of a dynamic web experience is not a new one, though not as widely adopted as one might think. To compete in today's e-commerce world, it is imperative to make your website personalised in this way. This means that when someone comes to your website and is supplying you with information through their behaviour, and perhaps explicitly through registration of their preferences, you push relevant content to the forefront. Pushing content to the forefront means that the visitor spends less time drilling down into the site. The brand experience then shifts from 'they supply everything to all athletes' to 'they cater to me and my sports'.

\section{Beyond the website - Connected Commerce}

Now let's take this a step further. Despite your best efforts, most of your visitors leave your site without converting. They may be on their way to your store, but chances are they are now on someone else's website looking for the same product or its substitute. So you have some options:

(1) Do nothing and hope they choose you.

(2) Develop a personalised website experience so if they do return they are met with those items they were browsing so intently.

(3) If they are opted in, send them an e-mail with those items and an appropriate offer.

As mentioned, number 2 is important, but in this scenario number 3 is going to deliver the greatest potential for a conversion. Some of you have developed abandoned shopping cart programs, sending an e-mail to someone who has left items in their cart. This is a step in the right direction, but you can vastly increase the size of your 'in-consideration' audience. The number of opted-in people hitting your website is likely 20 times that of those opted-in who put something in the cart but don't convert. To not address this significant audience's interests is a missed opportunity to close a sale, but also to demonstrate your attentiveness to their needs. Additionally, there is a likelihood of this audience purchasing 10-15 times more than your e-mail database audience. ${ }^{2}$ Yet, when it comes to e-mail marketing, you are spending the majority of your time focused on the entire database. We're not suggesting that you do away with your broad approach completely, but we recommend that a percentage of your efforts migrate to a narrow focus on 'in-consideration' opportunities. By 'in-consideration', we mean people who are actively engaged with your website now.

\section{Run the numbers}

For those of you wearing your analytics hat, run some of these numbers. Assume that mailing to your overall audience once per week 
will generate a 0.2 per cent conversion rate (conversions/net mailed). We'll assume 1,000,000 net mailed per campaign.

$$
\begin{aligned}
& 1,000,000 \text { net mailed } \times 0.2 \% \text { conversion rate } \\
& =2,000 \text { conversions }
\end{aligned}
$$

Then consider how many people are both opted into your e-mail program and visit your website per day. We've made some assumptions ${ }^{3}$ :

$$
\begin{aligned}
& 50,000 \text { visitors } / \text { day } \times 10 \% \text { opted in } \times 3.9 \% \\
& \text { conversion rate } \times 7 \text { days }=1,365 \text { conversions }
\end{aligned}
$$

\section{The automated message is an annuity that keeps on giving}

Now to be fair, we assume that some of those people might have converted without receiving the e-mail or perhaps because of your broad e-mail. ${ }^{4}$ So let's assume a net of 1,000 . This means that if you have no 'in-consideration' marketing programs in place today, adding them will give you: $1,000 / 2,000=\mathrm{a} 50$ per cent increase in conversions. That's a number you can't ignore.

Many of you may be asking yourselves, 'what about the level of effort to get these programs in place?' We're glad you're thinking about this. Yes, an automated message requires more of an investment than a blanket-send to the entire database. But, consider that the message to the entire database is a one-time return on investment. By contrast, the automated message is an annuity that keeps on giving. Conversions keep pouring in and your ongoing investment is close to nil, perhaps an E-mail Service Provider (ESP) hosting fee. Jupiter did a study on this a few years ago in the US, providing both estimated relative revenues and profits from such programs (see Figure 2). The numbers are clearly enticing.

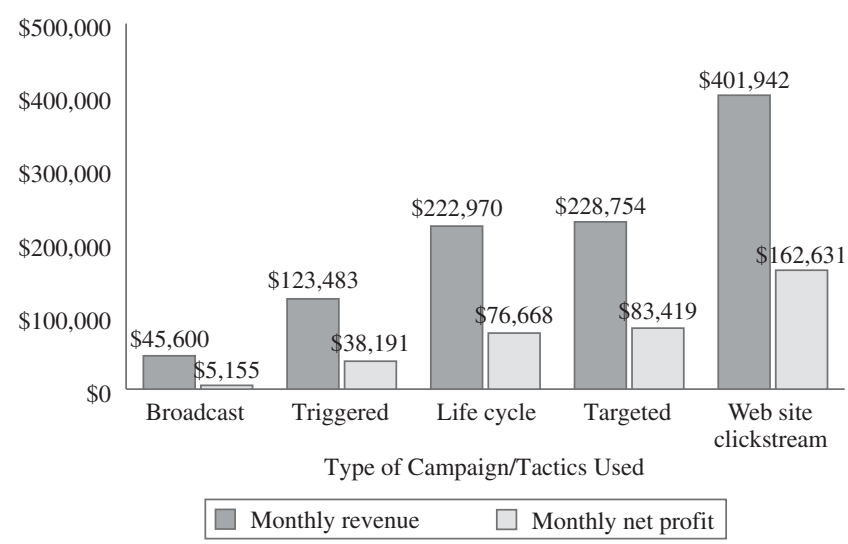

Figure 2: Relevance delivers more revenue and profit ${ }^{5}$ 


\section{Consumers are providing you with hints as to their intent as they engage with your digital content}

\section{Consumer experience vision}

Enough maths for the time being. Let's get to the good stuff. Consumers are providing you with hints as to their intent as they engage with your digital content. These implicit data nuggets constitute the 'listening' layer. This is where we the marketers receive input from the consumer who is expecting us to respond in kind, much like a conversation. Let's plot our customer experience vision for this market of sporting goods.

If a consumer searches for 'Nike Golf Clubs' on Google and arrives at a corresponding area on your site, you should take away a few things:

(1) This is a golfer.

(2) This person is in the market for golf clubs.

(3) This person's brand preference is Nike.

(4) This is a relatively high-end, high-consideration purchase.

Now, you might argue that this person is more than a golfer, and may be considering more than the Nike brand, or may in fact not be 'in-consideration,' but is just day-dreaming about something he can't afford. Despite the level of detail we can capture, marketing remains an inexact science. Focus on the information you have, not on what you don't.

So let's assume that our visitor does not make a purchase on this visit, but that he does opt-in for e-mail. He checks off that he likes golf and tennis, and that he is male. Let's now contemplate what e-mail messaging this person should receive from us:

(1) Message number 1: Welcome - Always welcome a new subscriber and do so immediately. This e-mail should contain visual and copy elements that repeat back to them what they've told you. Golf and tennis: our store is the place for you. It's also nice to share with them what they should expect to receive from you. This may just be a repeat of what you showed them on the site as they were subscribing. Some brands show tile images of newsletter e-mails and then provide a link to click to a recent message. A nice touch.

(2) Message number 2: Address the immediate interest - The next message should be even more specific to address the person's immediate consideration interest. That is, this message should be about golf, and should highlight the benefits of the Nike golf clubs. It could contain some secondary tennis content, but we would suggest leaving it out for now. Finally, this message should not contain paint ball or kayak offers! To those marketers who believe that a consumer focuses on what's relevant to them and turns a blind eye to the irrelevant content, you're wrong. There is nothing more off-putting than these circular 'everything we offer' messages. In case you've already put it out of your mind, we refer you back to Figure 1 - Typical New Subscriber Disengagement due to Irrelevant Marketing.

(3) Message number 3: Stay on message - Because these golf clubs are expensive and require some consideration, we suggest staying 
on topic for the next message. We should make the assumption that this person has not made a buying decision yet. At this point, there is no reason to stray from Nike and have the consumer put off their purchase by considering five other brands. They knew what they wanted and you have it, full stop. This is a great opportunity to show the customer reviews of the Nike golf clubs from industry periodicals, but more importantly, from their peers. Recommendations from others significantly contribute to buyer confidence and thus decision-making. The absence of peer reviews is a deterrent to purchasing from you, particularly when your competition provides them.

(4) Message number 4: Abandoned shopping cart - We've made progress. The customer has put a set of Nike irons into the cart, but has not yet purchased. So, the next day we should try to close this deal. With golf clubs, our margin is significant enough that we offer free delivery. Let's remind this customer of this, and that we offer a 30-day money back guarantee. This should relieve his concerns and get him to take the leap. Note that, because of this event, we've now removed this customer from the web-activity email stream and put them into the abandoned-cart stream.

(5) Message number 5: Purchase confirmation - Success. The customer has purchased a set of Nike irons for $£ 369$. Rather than simply sending a formal receipt, why not include an image of the product and the positive reviews. This will help the customer feel good about his purchase, minimising the chance of a cancellation should buyer's remorse set in. Additionally, we have the opportunity to include other products that are relevant to this customer, such as a Nike driver and some Nike golf balls. Note that, because the customer converted, we've now removed him from the abandoned cart e-mail stream.

We have just created a use case scenario. It is an exercise that you and your team should carry out regularly. It is the process that brings you to customer-centric marketing. Remember to check your constraints at the door. In typical brainstorming best practice, forget what you believe cannot be done. If the ideas generated are truly great, it may well be worth the time and effort to deliver that experience to your customers. These sessions can be a lot of fun, and a nice break from the rigour of the blanket-mailing schedule.

\section{Vision to reality - Connected Commerce}

Speaking of constraints, now that we've devised this personalised vision, we should address what you are no doubt thinking: 'This is a great fantasy, but is this really achievable?' The answer is a resounding 'Yes!'

There are three things necessary to get you there:

(1) Product recommendation model — we are going to demonstrate how a model's output connects with content information to enable this type of personalisation. 


\section{We need to gather implicit and explicit preference data}

(2) Content development process - we are going to address how the digital marketing team should be spending their time.

(3) Technology — we are going to outline the Connected Commerce infrastructure you'll need to achieve this vision.

\section{Product recommendation model}

As we went through our use case, you may have noted that we were keying off very specific terms: a specific brand and a specific product. As we know, the website visitor is not always so specific. They often come to your site to determine which product they need. In order to furnish people with appropriate product recommendations, we need to establish a means of gathering implicit and explicit preference data and translating that into the appropriate content presentation.

We refer to the user data capture process as the 'listening' layer. In order to devise a model from user data, you need a producttaxonomy. A product-taxonomy is a tiered categorical definition of your products. It is a hierarchy of terms that describes the product at a high level, down to the specific Stock Keeping Unit (SKU). The good news is that you may already have one. In developing the Search capability on your website, a taxonomy was likely created. Otherwise, one was created when your Search Engine Optimization (SEO) or Paid Search programs were devised. If these areas fall into your area of responsibility, you know what you have to work with. If they don't, you will need to head down the corridor to find these specifications from your web or advertising teams. If nothing is in place, get yourself an intern and put them to work.

Here's what a taxonomy might look like in this case (Figure 3):

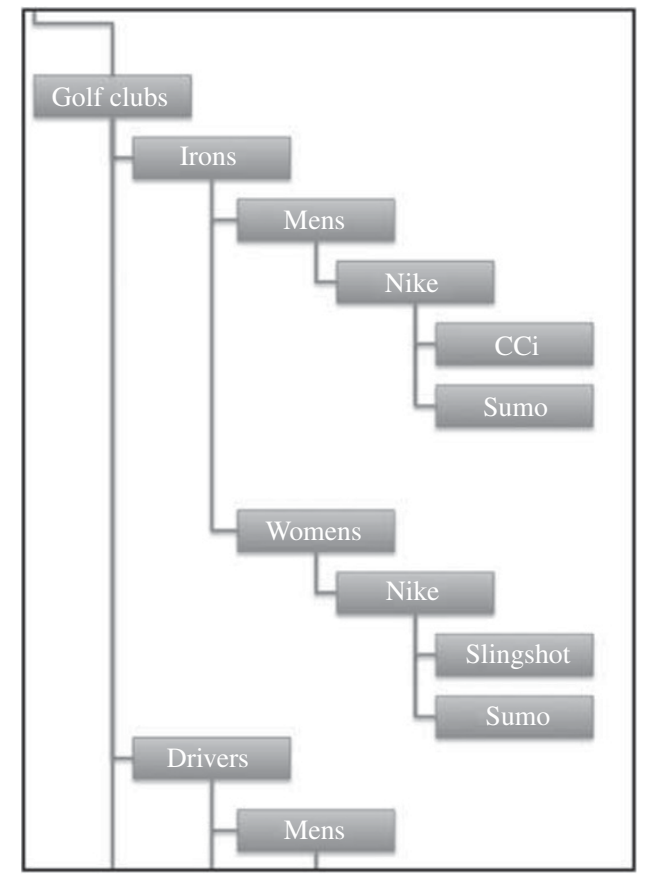

Figure 3: Product taxonomy example 
Table 1: User model output table

\begin{tabular}{lllllllll}
\hline User ID & Gender & Brand 1 & Brand 2 & Brand 3 & Category 1 & Category 2 & Product type & Club model \\
\hline 971650372 & Male & Nike & - & - & Golf & Tennis & Golf irons & CCi \\
\hline
\end{tabular}

Table 2: Product table

\begin{tabular}{|c|c|c|c|c|c|c|}
\hline SKU & Brand & Gender & Product type & Club model & Price & Name \\
\hline 87362195 & Nike & Male & Golf irons & $\mathrm{CCi}$ & $£ 369$ & Men's CCi irons \\
\hline 87362199 & Nike & Male & Golf irons & Sumo & $£ 359$ & Men's sumo irons \\
\hline 87363199 & Nike & Female & Golf irons & Sumo & $£ 359$ & $\begin{array}{l}\text { Women's sumo } \\
\text { irons }\end{array}$ \\
\hline 87363194 & Nike & Female & Golf irons & Slingshot & $£ 419$ & $\begin{array}{l}\text { Women's } \\
\text { slingshot irons }\end{array}$ \\
\hline
\end{tabular}

The taxonomy now must be matched to your product content. For each taxonomy element on the data side, you need a corresponding element on the content side. This is again similar to how your onsite search functionality results in a bunch of products based on a search term. In this case, however, we are not going to display a page full of products. We want to get down to an indexed order of products so that 1 or 2 or maybe 3 products are displayed in an e-mail or on a webpage side column - whatever our template dictates. So, our need to 'push' content to the user requires an additional level of logic. There must be an index to filter down to the product or products you want to present. Thus, when your customer-supplied information doesn't take you all the way down to a specific SKU, you need some means of getting there. We believe that this is a great opportunity to get the input of merchandising.

So, how does all this work together? The relationship of these tables to arrive at the appropriate SKU index would look something like Table 1.

This is a summary user model output for our user. The underlying logic of the model is deeper than we will go into in this paper. Suffice it to say, a simple scoring logic is used to assign point values to each explicit data value and implicit activity value. The result is a prioritised output record as above, which will be matched to Table 2 to deliver the appropriate content.

The product table is simply organised to contain the elements from the product hierarchy.

\section{Content process}

As data issues subside, Over the last few years, digital marketers have taken on massive data the next bottleneck becomes apparent: content challenges with varying success. As data issues subside, the next bottleneck becomes apparent: content. Lack of content is replacing data challenges as the primary gap in customer-centricity. To deliver on the customer-centric experience, content must be available for all the 


\section{No longer can your creative team cut an image and write copy for a single spot on the website}

products you sell online. It needs to be website-ready, but it also needs to be available to your other channels, primarily e-mail, but potentially mobile if that's a channel in which you operate. So moving forward, product content should have the following:

(1) Multi-channel availability - no longer can your creative team cut an image and write copy for a single spot on the website. They should create an e-mail (and a mobile) version too. This may be a single image and copy block per channel, or it may be something shared across channels. Although this may seem like a lot of additional work, most creative teams are using applications today that allow for rapid cutting of images to predetermined dimensions. Also, keeping dimensions proportional across template slots makes this a whole lot easier.

(2) Product taxonomy - each new product must be assigned taxonomy values so that it can be identified by your model for presentation through any digital channel. The best way to do this is to assign someone the role of product taxonomy, so that as new products are introduced they are categorised before they make their first appearance on the website. Under our proposed model, an uncategorised product is useless, as it will not show up in any model result.

Now, because we are staying focused on a single product for this user, the email template we are using only calls for one product to be inserted. The elements fall into place using simple merge logic. So for example, if we want a large image of the men's CCi irons, the template would contain an image reference for http://images.ed4.net/client= 728562/_SKU__Large.gif.

The SKU simply merges into the image URL reference. Now it should be clear that the naming of all of the imagery and copy blocks must follow a specific nomenclature. Thus, the content library contains content with appropriate named content elements. This level of organisation is essential for the presentation layer in Connected Commerce.

\section{Technology}

The technology required to deliver on the customer-centric vision might already be at your fingertips. Most marketers have some or all of the components they need, but rarely are they integrated. Thus, Connected Commerce is the frictionless data synchronisation between the listening layer, the decision layer and the presentation layer (see Figure 4). Here's what you need:

(1) Listening layer - In order to capture your customer's intent, you must have a system to capture their actions and categorise them appropriately based on your taxonomy. Several e-commerce platforms provide this capability, as do one or more ESPs. Web Analytics providers also gather this information if appropriately

\author{
We recommend a \\ dedicated e-Data \\ Mart for collection \\ and processing of this \\ information
}




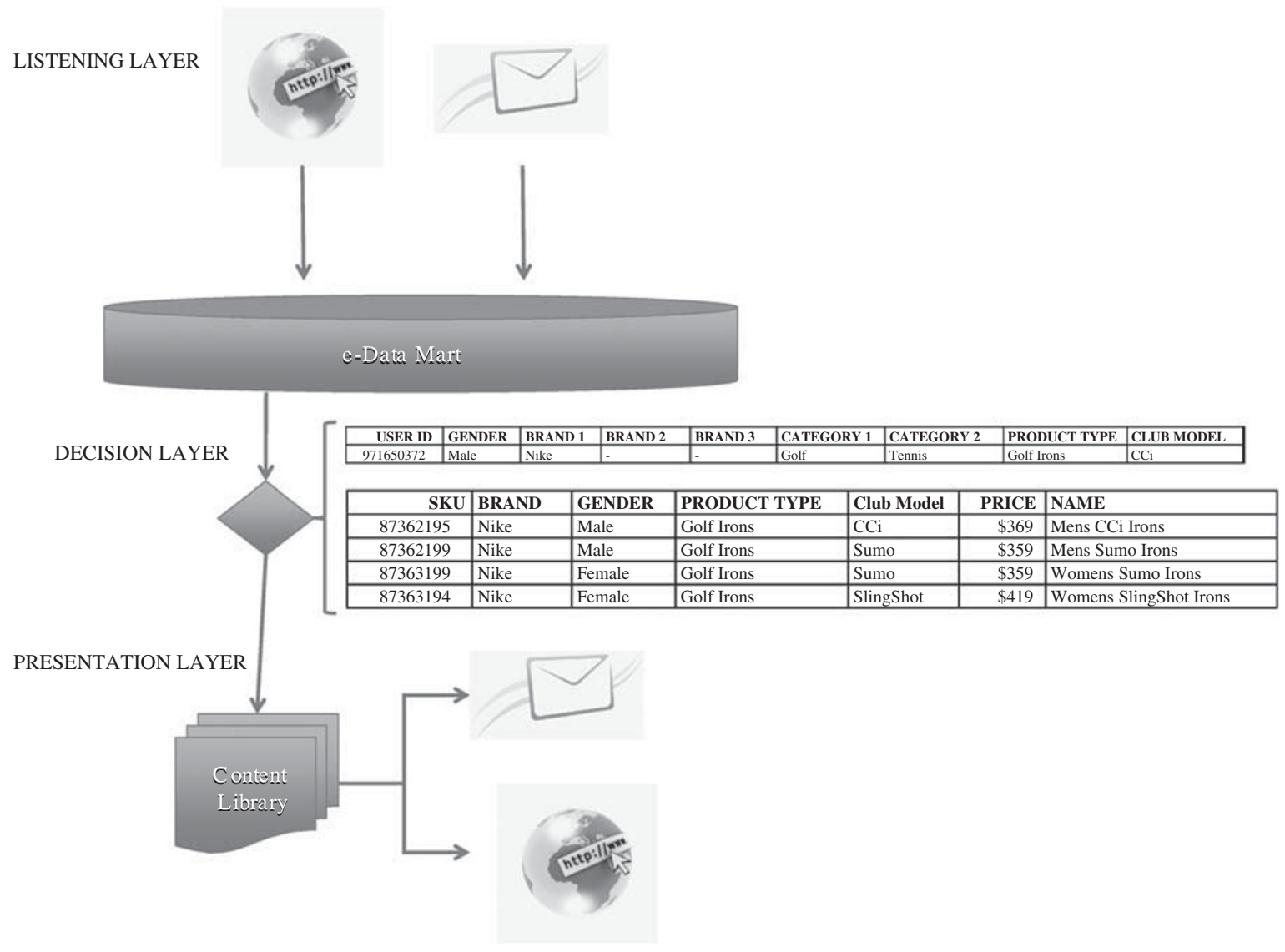

Figure 4: Connected Commerce infrastructure

configured. Because of the speed at which this data will be necessary for presentation layer personalisation, it cannot be maintained in a slow data warehouse. We recommend a dedicated e-Data Mart for collection and processing of this information. This gives the digital marketer ready access to the information for quick audience analysis and selects, and rapid targeting in their preferred digital channels.

(2) Decision layer - Translating your use case into reality requires the development of automated business rules. Your e-commerce platform likely has this capability for the website. The higher-end ESPs have this capability for e-mail. If your model needs a home, because your solution providers don't have the capability, consider some of the product recommendation applications on the market.

(3) Content library - A content library is software that provides for the actual storage and organisation of all of your content. The organisation refers to the taxonomy described above. So, when the decision layer says pull SKU \#596832876 content for an e-mail, the system pulls the right content for the right channel. 
(4) Presentation layer - e-commerce platform with custom publishing capability - Your e-commerce solution should either have the above features or should integrate with third-party solutions. If it does not, you are due for a web technology overhaul.

(5) Presentation layer - ESP with custom publishing capability Your ESP must have the capability to pull content from a content library based on automated business rules. This is critical to building customer-centric communications.

These are the components, but integrating them is another matter. If you're like most digital marketers, your infrastructure consists of a number of different components that don't talk to each other. If this is the case, determine which ones have integration capabilities through APIs and which ones are bound for the bin. If you are in the market for a new infrastructure, look for solutions where the ecommerce platform has the above components and is seamlessly integrated with an ESP. This is Connected Commerce, and it will save you from having to hire consultants to cobble a system together for you. The expense and lost time of this alone is worth the added expense of an out-of-the-box, frictionless data synchronisation solution.

\section{Conclusion}

As a digital marketer, you're in a position that your predecessors only dreamt of. To have access to your customers' behaviour is the nirvana of marketing. Yet, the majority of digital marketers are not taking advantage of this data, because they are not translating it into actionable information. Your customers are leaving you clues as to their immediate interests, but they're receiving a generic response. This is understandable. The road to get from an internally driven marketing process to one that truly leverages customer interests seems a long one.

Advancements in technology have made this achievable for more than just the early adopters, however. Connected Commerce is now accessible even for those who have been waiting to see how it will play out. The waiting is over. It is time to get started. It is time to get out of the blanket treatment, promotional calendar mindset. Although it may feel like a risk to change your strategy, leaving this comfort zone is the only way you will maintain a market position and ultimately move ahead in your industry. Your customers' expectations of personalised treatment have risen dramatically. They are granting their loyalty to the handful of brands that really speak to them. Speaking to them means addressing their immediate needs and not inundating them with irrelevant content for them to sift through until they find what they want. Their attention spans are too limited. Immediate access has become the norm. So, give your customers what they want. Begin today. Make their experience truly personal and relevant. You will be rewarded with conversions, loyalty and positive customer sentiment. 


\section{Connected Commerce 孮}

\section{References and Notes}

1. Our experience has shown that there is a difference in relevance acceptance by subscribers based on industry. When people are buying a household staple such as groceries they are less discerning, because they are 'always in the market' for the products. That said, if someone engages with multiple grocery brands through websites and e-mail, the brand that is delivering greater relevance is likely to gain an advantage.

2. Metrics used to derive this metric: 0.2 per cent conversion rate for blanket e-mails to entire audience. Provided by e-Dialog. 2-3 per cent conversion rate on retail websites, provided by emarketer.com, Source: Shop.org and Forrester Research, June 2006.

3. JupiterResearch. (2005) 'The ROI of e-mail relevance - Improving campaign results through targeting' Volume 1. JupiterResearch's study found that e-mail programs incorporating targeting from web activity generated a 3.9 per cent conversion rate.

4. We aren't going to spend time on test and control measures here, but we recommend using a control group to ascertain just how many people are converting from these messages that would not otherwise. That is, automatically withhold a sample of the audience as a control, and analyse what percentage of those people returned through some other means to convert. The difference between your conversion rate from the automated mailings and this group is your net conversion from the automated message program.

5. JupiterResearch. (2005) 'The ROI of e-mail relevance - Improving campaign results through targeting' Volume 1. Figure 7. 